\title{
Application of Lateral Approach for the Removal of Migrated Interbody Cage: Taphole and Fixing Technique
}

Jae Sung Eom,

Ikchan Jeon, Sang Woo Kim

Department of Neurosurgery, Yeungnam University Hospital, Yeungnam University College of Medicine, Daegu, Korea

Corresponding Author: Ikchan Jeon

Department of Neurosurgery, Yeungnam University Medical Center, Yeungnam University College of Medicine, 170 Hyeonchung-ro, Nam-gu, Daegu 42415, Korea

Tel: +82-53-620-3790

Fax: +82-53-620-3770

E-mail: jicns@hanmail.net

Received: January 4, 2017

Revised: February 5, 2017

Accepted: February 6, 2017

Copyright (C) 2017 by The Korean Spinal Neurosurgery Society

This is an open access article distributed under the terms of the Creative Commons Attribution Non-Commercial License (http://creativecommons.org/licenses/by-n $\mathrm{c} / 4.0 /$ ) which permits unrestricted non-commercial use, distribution, and reproduction in any medium, provided the original work is properly cited.

When a revision surgery related with removal of failed interbody cage is required, going through the previous passage can lead to a higher risk of neurological deficits or incidental dural injuries. Recently, the lateral approach has become a popular method instead of the conventional anterior or posterior approaches. The lateral approach is also useful method to remove failed interbody cage previously placed and re-do interbody fusion with lower risks compared to revision surgery via previous passage. However, there is still some difficulty in retrieving the interbody cage from the intervertebral space because of no spacious passage, subsidence, and uncontrolled movable cage. In this study, we introduce our experience that we removed failed interbody cage more easily with only the simple additional steps of making a taphole and fixing the cage using a thread-tipped stick.

Key Words: Lateral approach, Reoperation, Device removal, Lumbar

\section{INTRODUCTION}

As cases of spinal surgery increase, the number of revision cases also increases. Cases with prior posterior lumbar fusion have several challenges, including epidural scar tissues, fibrosis, and anatomical changes. In particular, when the removal of interbody devices is required, going through the previous passage by creating a pathway in the unfavorable anatomical environment can lead to a higher risk of neurological deficits or incidental dural injuries following revision surgery.

Recently, the lateral approach has become a popular method instead of the conventional anterior or posterior approaches, ${ }^{4,9)}$. This approach has several advantages, such as reduced invasiveness and minimal perioperative neural injury. By using this method in revision surgery to access the interbody space, we can reduce complication risks, such as nerve root retraction and neural injuries associated with the posterior approach as well as vascular injuries associated with the anterior approach ${ }^{7}$. In addition, the lateral approach allows for a bigger interbody cage and fusion bed to achieve successful interbody fusion.

In this report, we have presented our clinical experience in using the lateral approach to remove an unfused and migrated interbody cage and to achieve interbody fusion with another new interbody cage.

\section{CASE REPORT}

\section{Case}

We studied the case of a 76-year-old male patient who had left hip and leg pains for 4 weeks. He had a transforaminal lumbar interbody fusion on the L4-5 segments for both leg and back pains under a diagnosis of stenosis and instability of the same segments 6 months ago. Computed tomography revealed a displacement of the interbody cage into the left subarticular zone of the spinal canal. There was also subsidence around the interbody cage at the 4th and 5th vertebral bodies, and periscrew loosening (identified by a halo effect) was observed in all transpedicular screws. Magnetic resonance imaging demonstrated a severe spinal canal stenosis on L4-5 with compression of the left L5 nerve root by the migrated interbody cage (Fig. 1).

\section{Operative Technique}

First, the rods connected to the loosened pedicle screws on L4 and L5 were removed in posterior revision to create a sufficient interbody space by retraction with the lateral approach.

Once the lateral disc space was reached via the lateral approach, we followed a procedure for detaching the interbody cage from the L4 

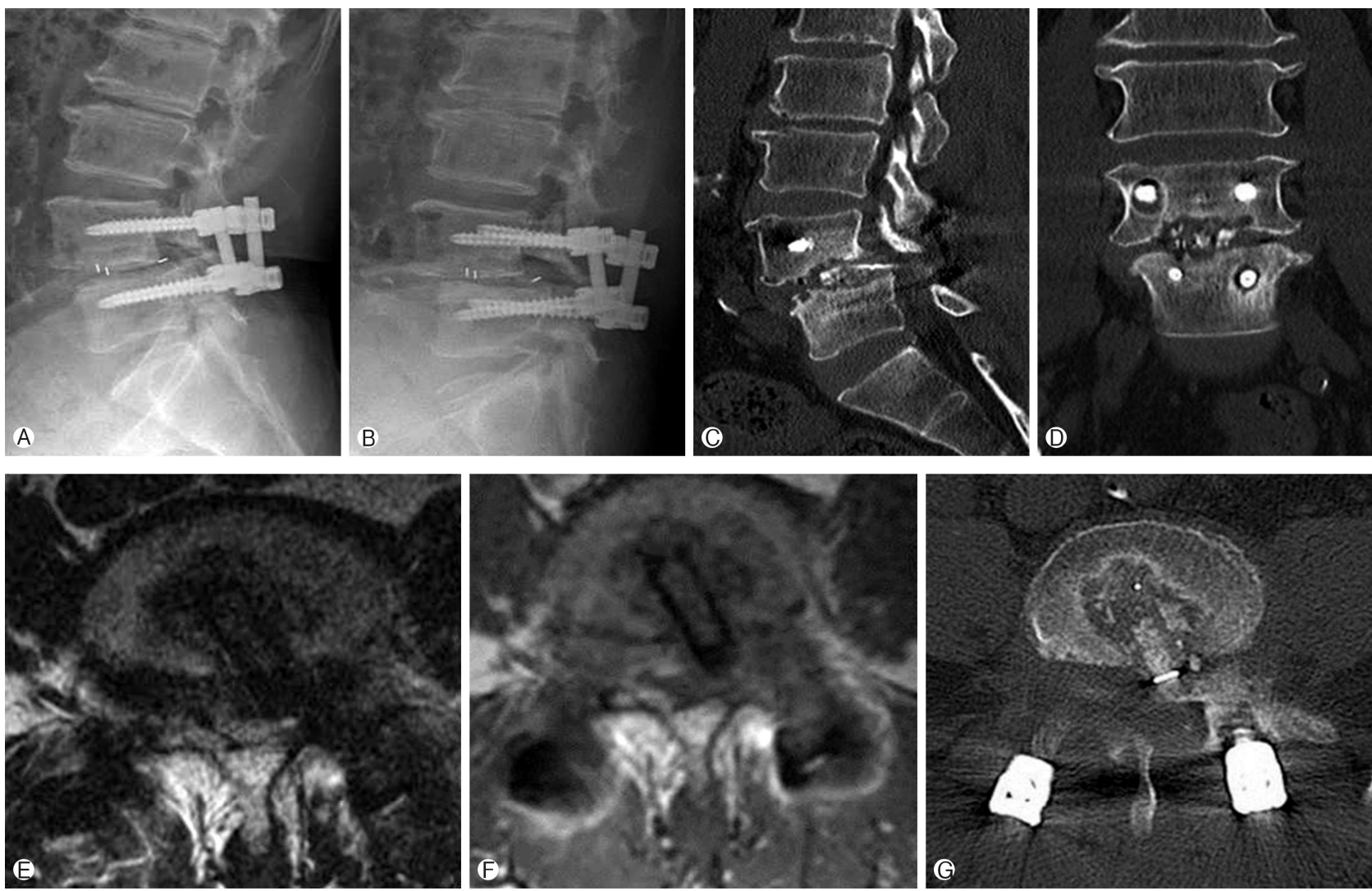

Fig. 1. Dynamic X-ray shows pseudarthrosis at L4 and L5 level (A, B). Computed tomography revealed a displacement of the interbody cage into the left subarticular zone of the spinal canal $(\mathrm{C}, \mathrm{D}, \mathrm{G})$. There was also subsidence around the interbody cage at the 4th and 5th vertebral bodies, and periscrew loosening was observed in all transpedicular screws. Magnetic resonance imaging demonstrated a severe spinal canal stenosis with compression of the left L5 nerve root by the migrated interbody cage (E, F).

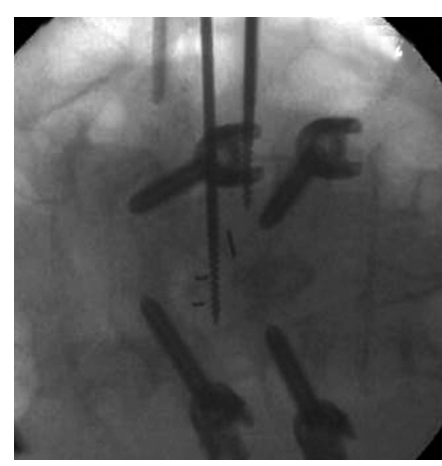

Fig. 2. Screw thread tip was fixed on the interbody cage via the ready-made taphole before loosening and moving the interbody cage from the intervertebral space. Subsequently, a complete loosening of the interbody cage from the endplates and surrounding connective tissues was achieved; the cage was then removed from the intervertebral space.

and L5 endplates using a Cobb retractor and osteotome. We made a gap between the interbody cage and endplates of the 4th and 5th vertebral bodies to make them movable and loose. After the interbody cage was completely loosened with additional curettages for surrounding scar tissues, we attempted to remove the interbody cage with a hook or pituitary force.

However, the presence of subsidence entrapped the interbody cage into the body, and the interbody cage was difficult to remove from the intervertebral space. In addition, when the interbody cage started to rotate or move away during the catching

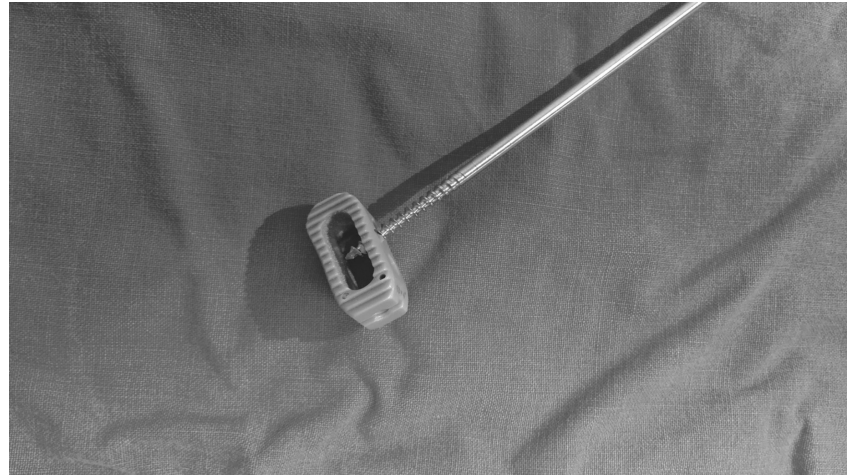

Fig. 3. A long stick with a screw thread (2-mm diameter) at the tip was fixed on the interbody cage via the ready-made 1 -mm-sized taphole.

and holding process, the situation became unfavorable, requiring additional time to complete the retrieval of the interbody cage. We also experienced these unfavorable situations several times before.

To avoid these situations, we designed and added new steps into the abovementioned process. A taphole (1-mm diameter) 
was first made on the surface of the interbody cage before loosening and moving the interbody cage. Thereafter, a long stick with a screw thread (with the bigger diameter size than that of the taphole, we used 2-mm diameter in this patient) at the tip was fixed on the interbody cage via the ready-made taphole (Figs. 2, 3). Subse- quently, a complete loosening of the interbody cage from the endplates and surrounding connective tissues was achieved; the cage was then removed from the intervertebral space.

The endplates of the disc space were prepared as a fusion bed, a new cage was inserted, and a lateral interbody fusion was performed. A posterior pedicle screw fixation was then added from L3 to S1, and pedicle screws with bigger diameters were used on the previous screw holes on L4 and L5.

\section{DISCUSSION}

Revision surgery can be a technically challenging procedure that deals with epidural fibrosis and scar tissues from the previous surgery to reach the surgical target. During these procedures, we can encounter an increased risk of incidental durotomy and nerve root injury by direct damage or traction ${ }^{2,13)}$. In particular, when a revision surgery is associated with failed hardware, which is an interbody device such as a cage affecting the neural structures and inducing neurological problems, decompression with device removal is necessary for neurological recovery ${ }^{1)}$. Unfused and migrated interbody cages can induce back pain caused by instability and radiculopathy from compressions of the nerve root. These conditions require interbody fusion as well as neural decompression by performing revision surgeries.

The removal of these failed interbody cages is typically performed via anterior or posterior revision surgeries. We assumed that the posterior approach might be more common in these situations because of anatomical familiarity. However, there are issues depending on the type of approach used. The anterior approach has the risk of injury associated with the great vessels, nerves (hypogastric nerve complex), or bowels during the surgical process and removal of the interbody cage ${ }^{5,10,12)}$. In addition, there is frequently a need for more extensive surgeries. Glassman et al. ${ }^{3)}$ described a successful anterior technique for cage removal. However, this procedure ultimately requires a partial vertebral body resection. Oh et al. ${ }^{8)}$ similarly used the anterior approach for removal and replacement of the interbody cage; however, in this particular study, the patient also required a posterior approach for revision of the segmental instrumentation.

In the posterior approach, epidural fibrosis from the prior surgery can alter the natural planes and anatomical landmarks, making the process challenging even though spine surgeons have anatomical familiarity with the approach ${ }^{13)}$. With this approach, increased dural retraction and nerve root mobilization are inevitable, and the risk of nerve damage is increased as surgeons attempt to expose a target site. The procedures performed on the neural structures may also cause leakage of the cerebrospinal fluid by dural tear. In addition, injuries to the posterior structures, such as muscles and ligaments can cause postoperative my- ofascial pain or infection ${ }^{2)}$.

The lateral approach allows passage to the anterior lumbar spine with the ability to avoid obstacles encountered in the anterior and posterior approaches. Besides its ease and minimally invasive direct access to the anterior lumbar spine, the technique increases safety by avoiding an area that has been affected by previous surgeries ${ }^{6}$. However, the lateral approach also has disadvantages associated with the approach pathway. Because of the nature of the muscle splitting approach through the psoas as well as the close proximity to the lumbar plexus, transient nerve injury can occur, causing temporary pain, weakness, or numbness ${ }^{11)}$. If injured, these nerves can have detrimental consequences; thus, neurophysiologic monitoring is required during the surgery ${ }^{11}$.

Moisi et al. ${ }^{6}$ already described retrieving the interbody cage using the lateral approach. They concluded that the lateral approach has many advantages, such as avoiding the great vessels or neural injuries encountered in the anterior or posterior approaches as mentioned above. Further, they usually remove the interbody cage with a hook or pituitary forceps. However, there are also some considerations depending on the location of the interbody cage under the presence of subsidence like our case. In addition, these problems develop when there is difficulty in retrieving the interbody cage from the disc space with no spacious passage. In situations with a narrow removal passage, movable interbody cage, and difficulty in grabbing the interbody cage, the interbody cage can be pushed further in the anterior or posterior direction. After we had previously experienced these problems, we designed and added more steps to increase the ease of removing the interbody cage without migration to an unexpected direction. As mentioned and described above, the cage can be removed easily with only the simple additional steps of making a taphole and fixing the cage using a thread-tipped stick.

The lateral approach is a useful method to remove interbody cages previously placed and re-do interbody fusion with lower risks compared to revision surgery via anterior or posterior approaches. However, anatomical obstacles, such as a high iliac crest could result in difficulties in accessing the intervertebral disc space.

\section{CONCLUSION}

When revision surgery is required for removing interbody cages previously placed, the lateral approach can be an effective alternative option. The lateral approach can lower and avoid the risks associated with the anterior or posterior approaches. In addition, creating a taphole and fixing the cage using a thread-tipped stick can increase the ease of retrieving the interbody cage.

\section{CONFLICT OF INTEREST}

No potential conflict of interest relevant to this article was reported. 


\section{REFERENCES}

1. Aoki Y, Yamagata M, Nakajima F, Ikeda Y, Takahashi K: Posterior migration of fusion cages in degenerative lumbar disease treated with transforaminal lumbar interbody fusion: a report of three patients. Spine (Phila Pa 1976) 34:E54-58, 2009

2. Eichholz KM, Ryken TC: Complications of revision spinal surgery. Neurosurg Focus 15:E1, 2003

3. Glassman SD, Johnson JR, Raque G, Puno RM, Dimar JR: Management of iatrogenic spinal stenosis complicating placement of a fusion cage. A case report. Spine (Phila Pa 1976) 21:2383-2386, 1996

4. Kim SJ, Lee YS, Kim YB, Park SW, Hung VT: Clinical and radiological outcomes of a new cage for direct lateral lumbar interbody fusion. Korean J Spine 11:145-151, 2014

5. Lindley EM, McBeth ZL, Henry SE, Cooley R, Burger EL, Cain $\mathrm{CM}$, et al: Retrograde ejaculation after anterior lumbar spine surgery. Spine (Phila Pa 1976) 37:1785-1789, 2012

6. Moisi M, Page J, Paulson D, Oskouian RJ: Technical Note - Lateral approach to the lumbar spine for the removal of interbody cages. Cureus 7:e268, 2015
7. Nguyen HV, Akbarnia BA, van Dam BE, Raiszadeh K, Bagheri R, Canale S, et al: Anterior exposure of the spine for removal of lumbar interbody devices and implants. Spine (Phila Pa 1976) 31: 2449-2453, 2006

8. Oh HS, Lee SH, Hong SW: Anterior dislodgement of a fusion cage after transforaminal lumbar interbody fusion for the treatment of isthmic spondylolisthesis. J Korean Neurosurg Soc 54:128-131, 2013

9. Ozgur BM, Aryan HE, Pimenta L, Taylor WR: Extreme Lateral Interbody Fusion (XLIF): a novel surgical technique for anterior lumbar interbody fusion. Spine J 6:435-443, 2006

10. Patel AA, Spiker WR, Daubs MD, Brodke DS, Cheng I, Glasgow RE: Retroperitoneal lymphocele after anterior spinal surgery. Spine (Phila Pa 1976) 33:E648-652, 2008

11. Rodgers WB, Gerber EJ, Patterson J: Intraoperative and early postoperative complications in extreme lateral interbody fusion: an analysis of 600 cases. Spine (Phila Pa 1976) 36:26-32, 2011

12. Rothenfluh DA, Koenig M, Stokes OM, Behrbalk E, Boszczyk BM: Access-related complications in anterior lumbar surgery in patients over 60 years of age. Eur Spine J 23 Suppl 1:S86-92, 2014

13. Selznick LA, Shamji MF, Isaacs RE: Minimally invasive interbody fusion for revision lumbar surgery: technical feasibility and safety. J Spinal Disord Tech 22:207-213, 2009 